ÉGYPTE

monde arabe

\section{Égypte/Monde arabe}

3| 1990

Médiateur et métaphores 2

\title{
Crise du Golfe, annexe X : Frères musulmans :
}

Communiqué $\mathrm{n}^{\circ} 2$

Liwâ' Al-lslâm, 21 août 1990, nº 6

Muhammad Hamid Abu-I-Nasr

\section{CpenEdition}

\section{Journals}

Édition électronique

URL : https://journals.openedition.org/ema/1896

DOI : 10.4000/ema.1896

ISSN : 2090-7273

Éditeur

CEDEJ - Centre d'études et de documentation économiques juridiques et sociales

Édition imprimée

Date de publication : 30 septembre 1990

Pagination : 254-257

ISSN : 1110-5097

Référence électronique

Muhammad Hamid Abu-I-Nasr, "Crise du Golfe, annexe X: Frères musulmans : Communiqué $n^{\circ} 2$ ", Égypte/Monde arabe [En ligne], 3 | 1990, mis en ligne le 08 juillet 2008, consulté le 07 juillet 2022. URL http://journals.openedition.org/ema/1896 ; DOI : https://doi.org/10.4000/ema.1896

Ce document a été généré automatiquement le 7 juillet 2022

Tous droits réservés 


\section{Crise du Golfe, annexe X : Frères musulmans : Communiqué $\mathrm{n}^{\circ} 2$}

Liwâ' Al-lslâm, 21 août 1990, nº 6

Muhammad Hamid Abu-I-Nasr

1 Les Frères musulmans ont publié un communiqué dans lequel ils ont vivement dénoncé et refusé l'intervention militaire américaine dans la crise du Golfe, quelles que fussent les raisons invoquées par le gouvernement américain pour la justifier, et réclamé le retrait immédiat de ses troupes. Concernant l'invasion irakienne du Koweït, le communiqué a affirmé que la confrérie n'admet pas l'usage de la force dans les relations entre les États arabes, et s'oppose à toute intervention militaire d'un État arabe ou islamique contre un autre État.

2 Louange à Dieu, Seigneur des mondes, et paix soit sur notre maître Muhammad, le fidèle messager, et sur sa famille et tous ses compagnons...

3 Consciente de la gravité de la tragédie vécue par le monde arabe, la confrérie des Frères musulmans implore du fond du cœur le Tout-Puissant et le Très-Haut, le Plus Grand de ceux que l'on appelle à l'aide, Celui qui répond le plus généreusement à notre appel. Nous l'implorons de mettre fin aux tourments de la nation arabe et islamique et de soulager ses maux. La confrérie précise, face à la nation islamique en général et face à la nation arabe en particulier, la position qui est la sienne dans le contexte actuel :

Premièrement : La confrérie réaffirme la position déjà énoncée dans son communiqué du 11 Muharram 1401 hég. (3 août 1990) rejetant l'usage de la force dans les relations entre États arabes et s'opposant à toute intervention militaire d'un État arabe ou musulman contre un autre État.

5 Deuxièmement : Elle affirme en outre, comme elle l'a déclaré dans le communiqué cité ci-dessus, que les différends entre États arabes et islamiques doivent être réglés par des moyens pacifiques conformément aux dispositions de lachari'a, à laquelle adhèrent les peuples de le nation arabo-islamique, lumière qui leur éclaire la voie. Loi à laquelle ils se soumettent de leur plein gré; ces différends doivent être également soumis aux 
dispositions de la Charte de la Ligue des États arabes, du droit international et autres traités et lois régissant les relations inter-étatiques.

6 Troisièmement : La confrérie des Frères musulmans dénonce et rejette énergiquement l'intervention militaire américaine dans la crise du Golfe, quelles que soient les raisons invoquées par le gouvernement américain pour la justifier. Elle s'oppose à la présence de troupes militaires étrangères - américaines ou autres - dans la région et réclame leur retrait immédiat, leur présence étant inacceptable sur tous les plans et selon toutes les normes et susceptible de nous faire revenir à l'époque des protectorats et autres occupations manifestes de la région, voire d'autres pays du Moyen-Orient et de l'ensemble des pays du Tiers-Monde. Cela ramènerait le monde au temps de la colonisation, où les États européens conspiraient pour se répartir les peuples et les richesses d'Afrique et d'Asie, ou de tous les pays opprimés. Les États-Unis d'Amérique auraient dû adopter une position tranchante à l'égard de leur allié hébreu qui occupe des terres chères à la nation islamo-arabe, terres dont il a anéanti la majorité de la population et où les survivants ne cessent d'être la cible de persécutions et d'humiliations, terres où la vie, les biens et la dignité ont été ravis à leurs détenteurs, auxquels on refuse le respect de leurs droits élémentaires. Bien plus, les autorités d'occupation favorisent encore l'immigration des juifs de Russie, d'Europe, d'Ethiopie et du reste du monde pour les implanter dans les territoires palestiniens, ne laissant par là même aucun doute quant à leur dessein d'extermination. Elles œuvrent à la réalisation du rêve expansionniste que, du reste, elles ne dissimulent pas, celui d'un Israël qui s'étendrait du Nil à l'Euphrate. Face à elles, les États-Unis s'abstiennent de toute mesure coercitive. Au contraire, ils leur fournissent leur soutien matériel et moral et se dressent contre toute résolution unanime du Conseil de sécurité à rencontre de l'État sioniste.

7 L'on sait par ailleurs que l'armée américaine rassemble un grand nombre de juifs fanatiques qui nourrissent à l'égard de la nation islamique une haine implacable et s'acharnent à l'affaiblir par tous les moyens et à la priver de ses droits.

8 L'on sait également que la même armée rassemble un nombre non négligeable de militaires détenteurs de la double nationalité israélienne et américaine, servant simultanément dans les armées des deux pays. Or les lois américaines interdisent catégoriquement toute distinction entre juif et non juif, ce qui empêche le commandement militaire américain de pouvoir prendre des mesures écartant juifs et Israéliens des troupes opérant sur les territoires saoudiens et dans la région du Golfe. Cela fait trembler les musulmans du monde entier, car l'Arabie Saoudite regroupe les Lieux saints musulmans, leur Qibla, la ville de leur Prophète et sa tombe.

9 Quatrièmement : Il aurait fallu, avant d'ouvrir la voie à la présence américaine dans la zone du conflit - ou sous réserve de son évacuation - créer une force arabe venant de pays arabes ou islamiques jouissant de la confiance du Royaume saoudien, des autres pays du Golfe et de l'Irak, comme l'Égypte, l'Algérie, le Maroc ou le Pakistan ; ces pays auraient fait barrage aux frontières pour empêcher une invasion irakienne de l'Arabie Saoudite ou d'autres États du Golfe. Une telle force aurait permis d'établir un climat de détente propice à la recherche d'une solution pacifique au conflit irako-koweïtien, solution qui préserverait les droits des deux parties. Mais avec la présence des troupes d'occupation américaines dans la région, que vont bientôt rejoindre d'autres troupes occidentales, il est absolument inenvisageable d'y envoyer des forces arabes notamment égyptiennes - car, cela va de soi, elles se trouveront dans une situation de 
dépendance vis-à-vis des États-Unis et de leurs alliés étrangers ; ces derniers auront le droit d'agir et de prendre toute initiative sans égard aucun pour les forces arabes notamment égyptiennes. Bien plus, ces troupes américaines et étrangères occuperont, lors de la conflagration, les positions les mieux protégées, tandis que les forces arabes occuperont les positions les plus exposées. Il est par ailleurs évident, comme l'indiquent les dernières nouvelles sur révolution des événements, que les troupes américaines et leurs alliés ne resteront pas longtemps en position de défense mais qu'elles se préparent à envahir l'Irak, à porter un coup fatal à ses institutions militaires, économiques et culturelles. Or la participation de forces arabes à l'écrasement du peuple irakien et de l'armée irakienne n'est en aucune manière acceptable. Et quoi qu'on pense du président Saddam Hussein et de sa politique, l'Irak, comme l'a dit le président Hosni Moubarak dans son discours d'ouverture du dernier sommet, représente pour la nation arabe un de ses principaux «affluents » et un élément essentiel de sa puissance militaire, économique, politique et sociale; il est impossible d'anéantir l'Irak, son peuple, ses institutions et ses sources de richesse; il est impensable que des troupes arabes prennent part à une telle entreprise, à titre principal ou secondaire.

10 Cinquièmement : Nous devons tirer de ces événements, avant qu'il soit trop tard, les leçons qui s'imposent, et ne pas perdre de vue ces paroles du Tout-Puissant : «Celui qui était mort, que nous avons ressuscité et à qui nous avons donné de la lumière pour se diriger parmi les hommes, est-il semblable à celui qui est dans les ténèbres et n'en sortira pas? » Oui, la nation islamique, arabe ou non arabe, demeurera aux prises avec les ténèbres de l'ignorance tant qu'elle ne reviendra pas à la raison, ne s'en remettra pas à Dieu, ne respectera pas rigoureusement les enseignements de sa religion et les dispositions de la chari'a, n'affirmera pas, par la voix de ses dirigeants, le respect des droits de ses peuples et la protection de leur dignité et de leur liberté... Tant que ces autorités n'auront pas reconnu le droit de leurs peuples à participer à la conduite de leurs affaires et qu'elles refusent de statuer avec eux sur tout ce qui concerne leur présent et leur devenir, ne leur donnant de droit que celui d'applaudir ce que leurs leaders applaudissent et de dénoncer ce que leurs leaders dénoncent. Il importe également que règne la fraternité entre les gouvernants et les peuples, conformément aux paroles du Très-Haut : "Les croyants sont frères », et celles de son Prophète : «Les croyants sont les uns aux autres les pierres d'une même bâtisse, ils se soutiennent mutuellement. » Il nous incombe en outre de bien saisir et de respecter ces paroles du messager de Dieu : «Si deux musulmans se combattent, celui qui tue et celui qui est tué sont voués à l'enfer » et "Aucun de vous ne sera croyant s'il n'aime pour son frère ce qu'il aime pour lui-même». Ainsi se concrétiseront ces paroles de Dieu: "Cette communauté qui est la vôtre est une communauté unique. Je suis votre Seigneur. Adorez-moi donc. »Si l'on considère la situation de la nation islamique, on peut constater qu'elle dispose de toutes les capacités économiques, sociales, culturelles, scientifiques et militaires qui l'autorisent à occuper une place de choix parmi les nations, grâce à sa morale, à ses vertus, à son savoir, à sa culture et à sa puissance. Cependant la division, le non respect des dispositions de la religion et de la chari'a nous a conduit à la faiblesse, à l'humiliation et au retard, au point d'être devenus des parasites.

11 Nous exhortons la nation islamique à sortir de son état de stupeur pour considérer les événements avec clairvoyance, distinguer le vrai et le faux, évaluer la situation selon les critères authentiques de la chari'a. Ainsi l'esprit de notre Seigneur - qu'il soit béni et 
exalté - ressuscitera en elle, elle pourra se relever de sa décadence et recouvrer sa grandeur et sa dignité: "Dieu a promis à ceux d'entre vous qui croient et qui accomplissent de bonnes œuvres d'en faire Ses lieutenants sur la terre, comme II le fit pour ceux qui vécurent avant eux. Il leur a promis d'établir fermement la religion qu'il lui a plu de leur donner, puis de muer leur inquiétude en sécurité. Ils l'adoreront exclusivement. » " Ô vous qui croyez, répondez à Dieu et à Son Prophète lorsqu'il vous invite à ce qui vous fait vivre. » « La puissance appartient à Dieu, à Son Prophète et aux croyants, mais les hypocrites ne le savent pas. »

Que Dieu protège notre nation des malheurs et des périls qui la guettent. Il n'y a de sauveur et de refuge que Dieu. Nous l'adjurons de nous épargner l'abandon et l'infortune. Nous implorons Sa bénédiction, Son pardon et Sa justesse, nous Le louons pour toute chose. Que Son salut soit sur le messager, envoyé par miséricorde pour les mondes, ainsi que sur sa famille et tous ses compagnons.

(La confrérie des Frères musulmans avait publié, à la suite de l'invasion irakienne du Koweït, un communiqué dans lequel elle avait qualifié celle-ci d'«acte horrible, consternant et stupéfiant ", et appelé au retrait des troupes irakiennes du Koweït, au respect de la légitimité de ce pays et à l'ouverture de négociations pacifiques pour résoudre le conflit opposant les deux pays.)

\section{AUTEUR}

\section{MUHAMMAD HAMID ABU-L-NASR}

Guide suprême de la Confrérie des Frères musulmans. 